This is an author produced version of a paper published in Journal of Neurochemistry. This paper has been peer-reviewed but does not include the final publisher proof-corrections or journal pagination.

Citation for the published paper:

Cenci, M Angela and Lundblad, Martin.

"Post- versus presynaptic plasticity in L-DOPA-induced dyskinesia"

Journal of Neurochemistry, 2006, Vol: 99, Issue: 2, pp. 381-92.

http://dx.doi.org/10.1111/j.1471-4159.2006.04124.x

Access to the published version may require journal subscription.

Published with permission from: Blackwell 


\title{
Post- versus pre-synaptic plasticity in L-DOPA-induced dyskinesia
}

\author{
M. Angela Cenci* and Martin Lundblad
}

Basal Ganglia Pathophysiology Unit, Dept. of Experimental Medical Science, Lund University, BMC F11, S.221 84 Lund (Sweden).

*To whom correspondence should be addressed. Angela.Cenci_Nilsson@med.lu.se

\section{Abbreviations:}

AIMs Abnormal involuntary movements

AMPA Amino-3-hydroxy-5-methyl-4-isoxazole proprionic acid

AP-1 Activator protein-1

CRE cAMP response element

CREB CRE-binding protein

DA Dopamine

DAT Dopamine transporter

DARPP-32 Dopamine and cAMP-regulated phosphoprotein of $32 \mathrm{kDa}$

ERK1/2 Extracellular signal-regulated kinases 1 and 2

L-DOPA L-3,4-dihydroxyphenylalanine

LTP Long-term potentiation

MPTP 1-methyl-4-phenyl-1,2,3,6-tetrahydropyridine

NMDA N-methyl-D-aspartate

6-OHDA 6-hydroxydopamine

PET Positron Emission Tomography

PKA Protein kinase A

PD Parkinson's disease 


\section{Abstract}

L-DOPA remains the most efficacious drug for the treatment of Parkinson's disease (PD), but causes adverse effects that limit its utility. L-DOPA-induced dyskinesia (abnormal involuntary movements) is a significant clinical problem that attracts growing scientific interest. Current notions attribute the development of dyskinesia to two main factors, viz. the loss of nigrostriatal dopamine (DA) projections and the maladaptive changes produced by LDOPA at sites post-synaptic to the nigrostriatal neuron. Basic research in the past 15 years has placed a lot of emphasis on the postsynaptic plasticity associated with dyskinesia, but recent experimental work shows that also some presynaptic factors, involving the regulation of L-DOPA/DA release and metabolism in the brain, may show plasticity during treatment. This review summarizes significant studies of L-DOPA-induced dyskinesia in patients and animal models, and outlines directions for future experiments addressing mechanisms of presynaptic plasticity. These investigations may uncover clues to the varying susceptibility to L-DOPA-induced dyskinesia among PD patients, paving the way for tailor-made treatments. 
Parkinson's disease (PD) is the second most common neurodegenerative disorder and affects $2 \%$ of the population over the age of 60 years (for review see Mayeux 2003; Gasser 2005). Although it has become increasingly clear that PD is a multisystem synucleinopathy (Braak et al. 2004), severe degeneration of nigrostriatal dopamine (DA) neurons is the pathological feature causing the typical parkinsonian motor syndrome (akinesia, rigidity, tremor, postural imbalance) that leads to diagnosis and treatment (for review see Fahn 2003). The DA precursor, L-DOPA produces a mild to dramatic reduction in all the symtoms and signs of parkisonism. However, the vast majority of responding patients eventually develop dyskinesia and motor fluctuations (for a recent review see Obeso et al. 2004; Olanow et al. 2004b). Dyskinesia (abnormal involuntary movements) is the earliest and most common isolated complication produced by L-DOPA (Rajput et al. 2002; Mazzella et al. 2005). A review of the cumulative literature shows that approximately $30 \%$ of PD patients experience dyskinesia after 4-6 years of L-DOPA treatment, and close to $90 \%$ of the patients suffer from this complication after 9 years (Ahlskog and Muenter 2001). L-DOPA-induced dyskinesia most typically presents with an idiosyncratic mixture of choreiform and dystonic movements that are most severe 40-80 minutes after a dose administration of L-DOPA (termed "on" or "peak-dose" dyskinesia, for review see (Nutt 1992; Fahn 2000). Clinical epidemiological studies have been concordant in identifying some prominent risk factors for dyskinesia, namely, young age at PD onset, disease severity and duration, higher initial L-DOPA dose and duration of L-DOPA treatment (Peppe et al. 1993; Blanchet et al. 1996; Grandas et al. 1999; Schrag and Quinn 2000). Some of these factors, i.e. PD severity and duration are directly related to the extent of striatal dopamine (DA) depletion (Seibyl et al. 1995; Morrish et al. 1996), while other factors, i.e, L-DOPA dose and treatment duration, reflect some action of L-DOPA in the brain. The interaction between DA denervation and L-DOPAtreatment is difficult to examine in PD patients, where pathological processes and medication regimens show large variation both between individuals and between different stages of the disease. By contrast, animal models of L-DOPA-induced dyskinesia allow for dissecting the impact of specific aetiopathogenic elements under strictly controlled conditions.

In both nonhuman primate and rodent species, models of L-DOPA-induced dyskinesia are produced by first injuring the nigrostriatal DA projection, and then administering L-DOPA once or twice a day for a couple of weeks (Cenci et al. 1998; Pearce et al. 1998; Di Monte et al. 2000; Lundblad et al. 2002; Lundblad et al. 2004) to months (Lee et al. 2000; Bezard et al. 2003). In these animal models, abnormal involuntary movements (AIMs) are seen for two-three hours after drug administration, thus reproducing the peak- 
dose variant of L-DOPA-induced dyskinesia. Studies in animals allow us to clearly distinguish two aspects in the dyskinetic action of L-DOPA. One aspect is the acute effect of single L-DOPA doses on the physical expression of dyskinesia. As illustrated in Fig. 1, a nigrostriatal DA lesion dramatically lowers the threshold dose of L-DOPA that can acutely induce dyskinesia (Jenner 2000; Lundblad et al. 2004). The other aspect is a long-term effect of the treatment, which accounts for an increasing incidence and severity of dyskinesia with repeated administration of L-DOPA (see e.g. Lundblad et al. 2002; Winkler et al. 2002). This effect may also account for a further reduction in the dyskinetic threshold dose of L-DOPA during a course of drug treatment (Fig. 1). The long-term effect of L-DOPA is indicative of maladaptive plastic changes that occur in the brain, and is often referred to as the "priming" effect of L-DOPA (Brotchie 2005). Indeed, an animal that has been primed to respond to a dose of L-DOPA with AIMs will continue to exhibit this dyskinetic response even after long periods of treatment discontinuation. In summary, dyskinesia can be elicited by acute LDOPA administration provided that the drug dose is sufficiently high and/or that the nigrostriatal DA pathway is severely damaged. However, repeated administration of L-DOPA will result in (i) a reduction of the dyskinesia-threshold dose, and (ii) a progressive aggravation and (iii) an increasing incidence of dyskinesia with the same drug dose. Chronic dyskinesiogenic treatment with L-DOPA will also establish a persistent predisposition to dyskinesia, which is seen as a prompt re-appearance of abnormal movements in response to a dose of L-DOPA even after long periods of treatment discontinuation. All these effects of the chronic drug treatment reflect maladaptive plastic changes in the brain. In the following, we shall discuss plastic changes of pathophysiological importance to dyskinesia that follow either nigrostriatal DA degeneration ("lesion") or L-DOPA treatment.

\section{Lesion-induced plasticity}

In human PD, clinical symptoms appear only after the loss of at least 50-60\% nigral DA neurons and 70-80\% DA content in the striatum (Marsden 1990; Fearnley and Lees 1991), implying that the nigrostriatal system has a remarkable capacity for functional compensation after partial damage. Studies in rats with 6-OHDA lesions have indeed shown that incomplete lesions mobilize a variety of homeostatic responses in the surviving DA neurons, including increased DA synthesis and release, a reduced rate of DA inactivation (for review see Zigmond et al. 1990) and vigorous axonal sprouting in the terminal arbours (Finkelstein et al. 2000; Stanic et al. 2003), which would normally be inhibited by a tonic stimulation of D2 autoreceptors (Parish et al. 2002). In 6-OHDA lesioned rats, the homeostatic capacity of the 
nigrostriatal DA system is overcome when $>70 \%$ of nigral DA neurons are lost (Finkelstein et al. 2000; Stanic et al. 2003), at which point profound molecular, neurochemical and behavioural derangements will start to appear. Importantly, severe DA denervation alters the routes of L-DOPA uptake and metabolism in the brain. When the dopaminergic system is intact (Fig. 2; top panel), the processing of exogenous L-DOPA occurs primarily in nigrostriatal neurons, where L-DOPA is converted to dopamine (DA) by aromatic L-amino acid decarboxylase (AADC), loaded into synaptic vesicles by vesicular monoamine transporter-2 (VMAT-2) (Nirenberg et al. 1995; Erickson et al. 1996), and released by physiological stimuli into the extracellular space. Clearance of DA from the extracellular space is ensured by the dopamine transporter (DAT), a highly efficient presynaptic reuptake mechanism present on the plasma membrane of nigrostriatal neurons (Miller and Abercrombie 1999; Raevskii et al. 2002). After (or even before) its reuptake, free cytosolic DA is subject to enzymatic break-down by monoamine oxidase (MAO) and catechol-Omethyl transferase (COMT). There exist other possible routes of cellular uptake and metabolism of L-DOPA in the brain, which increase in importance after a lesion of the nigrostriatal pathway (Fig. 2, lower panel). Serotonergic projections from the midbrain raphe nuclei to the striatum play a central role in the conversion of L-DOPA to DA in animals with 6-OHDA lesions (Arai et al. 1995; Tanaka et al. 1999). The importance of this route is even more pronounced in lesion models where DA denervation is accompanied by serotonergic hyperinnervation in the striatum (Guerra et al. 1997; Maeda et al. 2005). The presence of AADC (Arai et al. 1995) as well as VMAT-2 (Peter et al. 1995) in serotonergic fibers allows them to convert L-DOPA to DA, and to store DA in synaptic vesicles (along with serotonin), respectively. Vesicle storage would protect newly formed DA from breakdown by MAO and COMT enzymes, both of which are present in these cells. Impulse-dependent DA release from serotonergic terminals has been suggested to occur in the striatum (Miller and Abercrombie 1999; Tanaka et al. 1999) but the physiological importance of this phenomenon remains to be elucidated. In addition to serotonergic neurons, other cellular elements, both neuronal and non-neuronal (e.g. astrocytes), are capable of decarboxylating L-DOPA to DA (Melamed et al. 1980; Sarre et al. 1994; Brown et al. 1999). Several studies have shown evidence of intrinsic striatal dopaminergic cells which express AADC, DAT and TH immunoreactivity in PD patients (Porritt et al. 2000), primate models (Betarbet et al. 1997) and rat models (Lopez-Real et al. 2003) of PD. In some studies these cells have been shown to express $\mathrm{GAD}_{67}$ and to be morphologically similar to GABAergic interneurons (Betarbet et al. 1997). It has also been suggested that these neurons are newborn cells developed from 
neuronal progenitors (Porritt et al. 2000). The functional importance of these cells is however unclear, and their number is very low.

Cells and axon terminals that can convert L-DOPA to DA, but lack vesicular storage and/or high affinity reuptake capacity for DA, will provide a source of unregulated DA efflux into the extracellular space. Accordingly, studies in animal models of PD have shown that the brain's capacity for storage and clearance of exogenously derived DA is greatly impaired after a severe nigrostriatal lesion, resulting in abnormally large increases in extracellular DA following peripheral administration of L-DOPA (Abercrombie et al. 1990). A reduced capacity for MAO-A-mediated DA catabolism may also contribute to large increases in extracellular DA in the DA-denervated striatum (Wachtel and Abercrombie 1994). In turn, large fluctuations in extracellular DA levels are bound to elicit aberrant post-synaptic responses in dopaminoceptive neurons (Chase 1998).

\section{Clinical correlates: the presynaptic storage hypothesis}

Studies performed at the end of the eighties provided the first compelling demonstration that the response to L-DOPA changes with the progression of PD. By performing i.v. injections of L-DOPA in patients at different disease stages, Mouradian and colleagues (Mouradian et al. 1988; Mouradian et al. 1989) proved that the dyskinetic threshold dose of L-DOPA was significantly lower in advanced PD patients experiencing motor fluctuations compared to stable L-DOPA-responders. As a matter of fact, the therapeutic window of L-DOPA was lost in advanced PD, and the patients showed dyskinesia already at the lowest drug doses relieving their parkinsonian motor features. The difference between early and advanced PD was attributed to the progressive degeneration of nigrostriatal DA neurons, reducing the brain's capacity to take up L-DOPA, decarboxylate it to DA, store DA in vesicles, and gradually release it, as explained above. When DA storage capacity is compromised, the motor response to L-DOPA would be conceivably dictated by the bioavailability of this amino acid in the brain extracellular fluid, which changes over the time in relation to the drug dosing cycle (reviewed in Metman et al. 2000). The "presynaptic storage hypothesis" thus provided a first-level explanation for the occurrence of both motor fluctuations and dyskinesia, the latter being attributed to a periodic high-intensity stimulation of brain DA receptors (Metman et al. 2000). The hypothesis was backed by reports that a continuous i.v. infusion of L-DOPA over 24 hours produced a stable motor improvement with only mild dyskinesia in PD patients affected by motor response complications (Mouradian et al. 1987), Moreover, positron emission tomography (PET) studies had shown that the retention of ${ }^{18} \mathrm{~F}$ - 
labeled fluorodopa was reduced in the striata of fluctuating PD patients compared to stable LDOPA responders, compatible with the hypothesis of a more severe impairment in DA storage capacity in the former group (Leenders et al. 1986). Accurate pharmacodynamic analyses in larger groups of patients revealed, however, that the presynaptic storage hypothesis could not alone account for the profound differences in motor response between early and advanced PD (Nutt et al. 1992; Nutt and Holford 1996; Nutt et al. 1997). Moreover, it was found that also the pharmacodynamic profile of DA agonists changed during PD progression. Several studies reported that the response duration to apomorphine shortened, and its therapeutic window narrowed, in advanced parkinsonians compared to L-DOPA-naive patients (Bravi et al. 1994; Verhagen Metman et al. 1997). Since apomorphine does not require metabolic processing and storage in nigrostriatal DA neurons, these findings were interpreted as indicating that postsynaptic alterations account for the appearance of response complications to L-DOPA. The attention of basic investigators was thus shifted from pre- to post-synaptic factors in the search for the causal determinants of dyskinesia.

\section{L-DOPA-induced plasticity: post-synaptic changes}

Rats with unilateral 6-OHDA lesions have been instrumental for studying L-DOPA-induced plasticity at multiple levels using a variety of approaches. A body of data from this animal model point to a close relationship between dyskinesia and plastic changes in dopaminoceptive striatal neurons produced by L-DOPA. In rodents with nearly complete nigrostriatal degeneration, the abnormal involuntary movements (AIMs) induced by chronic L-DOPA treatment are much more tightly correlated with changes in gene expression in striatal neurons than with markers of presynaptic DA denervation, such as residual numbers of midbrain DA neurons or striatal density of DA fibers (Lee et al. 2000; Cenci 2002; Winkler et al. 2002). Among the post-synaptic changes so far examined, the striatal expression of prodynorphin (preproenkephalin-B) mRNA and FosB/ $\Delta$ FosB-related transcription factors has shown a particularly strong positive correlation with the severity of L-DOPA-induced dyskinesia (Cenci et al. 1998; Andersson et al. 1999; Winkler et al. 2002; Lundblad et al. 2004, Sgambato-Faure et al. 2005; Pavon et al. 2006). These two markers are persistently upregulated for weeks after discontinuing L-DOPA treatment (Andersson et al. 2003). In the dyskinetic striatum, FosB/ $\Delta$ FosB-like transcription factors account for a pronounced increase in protein-DNA binding activities at both activator protein-1 (AP-1) enhancers and cAMP response elements (CRE) (Andersson et al. 2001). These transcription factors have been implicated in the dyskinesia priming process by studies using antisense 
oligonucleotides against fosB/ $\Delta$ fosB mRNA (Crocker et al. 1998; Andersson et al. 1999). In one study, intrastriatal knockdown of fosB/ $\Delta$ fosB was found to inhibit both the upregulation of prodynorphin gene expression and the gradual increase in dyskinesia severity during a course of chronic L-DOPA treatment (Andersson et al. 1999). The intracellular process responsible for the observed upregulation of $\mathrm{FosB} / \Delta \mathrm{FosB}$ transcription factors (and, secundarily, prodynorphin mRNA) in DA-denervated striatal neurons is poorly understood, but different lines of evidence implicate an overactive signaling through D1 receptors. The striatal expression of D1 receptor mRNA is upregulated in L-DOPA-treated dyskinetic rats (Konradi et al. 2004), and the striatum-specific signalling protein, DARPP-32 is highly phosphorylated on threonine 34 (Picconi et al. 2003), which is expected to amplify D1dependent signal transduction through inhibition of intracellular phosphatases (Greengard et al. 1998). Importantly, D1 receptor-dependent G-protein activation has been found to be greatly enhanced in striatal neurons in a non-human primate model of L-DOPA-induced dyskinesia (Aubert et al. 2005), suggesting that the overactivity of D1-dependent signalling in dyskinesia begins with an increased coupling of D1 receptors to their transducing $\mathrm{G}$ proteins. In DA-denervated striatal neurons, D1-receptor stimulation is followed by a large activation of extracellular signal-regulated kinases 1 and 2 (ERK1/2) (Gerfen et al. 2002). These kinases can bring about changes in gene expression via phosphorylation of nuclear transcription factors, such as CREB and Elk-1 (Sgambato et al. 1998) (Fig. 3). The striatal activation of ERK $1 / 2$, and the upregulation of $\mathrm{FosB} / \Delta \mathrm{FosB}$ and prodynorphin are totally prevented when L-DOPA is coadministered with a selective D1 receptor antagonist (St-Hilaire et al. 2005; Westin et al. 2006a). The same coadministration regimen does also block the development of abnormal involuntary movements during the course of L-DOPA treatment (Westin et al. 2006a), further implicating a close association between the priming for dyskinesia by LDOPA and aberrant D1-dependent molecular plasticity in the striatum.

In addition to altering gene expression in striatal neurons, an enhancement of D1-dependent signalling is bound to affect the strength of glutamatergic corticostriatal synapses. These synapses undergo activity-dependent changes, which are pivotal to the learning and storage of both adaptive and maladaptive behaviours (for review see Calabresi et al. 1996; Gerdeman et al. 2003a), including dyskinesia (Chase and Oh 2000; Picconi et al. 2003). There is a juxtaposition between corticostriatal and nigrostriatal terminals on dendritic spines (Fig. 3), and D1 and NMDA receptors can bind to each other within the post-synaptic density of striatal neurons (Lee 2002; Fiorentini et al. 2003). This physical proximity allows for a tight 
functional interaction between glutamatergic and dopaminergic inputs in modulating the plasticity of corticostriatal transmission (Graybiel 1995; Reynolds et al. 2001). In particular, activity-dependent long-term potentiation (LTP) of corticostriatal synapses requires concomitant activation of NMDA and D1 receptors (Partridge et al. 2000; Kerr and Wickens 2001), while it is antagonized by D2 receptor-stimulation (Calabresi et al. 1997). A synergistic interaction between D1 and NMDA receptors is supported by a body of studies performed in cultured striatal neurons or slices, which have identified several possible mechanisms of NMDA receptor potentiation following D1 receptor stimulation, such as protein kinase A (PKA) dependent-phosphorylation of NMDA subunits (Leveque et al. 2000), enhancement of L-type calcium currents (Cepeda et al. 1998; Nicola et al. 2000), and increased surface expression of the NR2B subunit (Hallett et al. 2006). Given the requirement for D1 receptor stimulation in corticostriatal LTP, it is not surprising that this form of synaptic potentiation is abrogated by a severe lesion of the nigrostriatal pathway (Centonze et al. 1999). Treatment with L-DOPA restores corticostriatal LTP, but animals that develop dyskinesia during the treatment show a synaptic abnormality consisting in a loss of LTPreversal upon low-frequency stimulation of cortical afferents (Picconi et al. 2003). It is tempting to speculate that this abnormal, irreversible potentiation of corticostriatal synapses may contribute to dyskinesia by disrupting the ability of striatal neurons to discriminate between relevant and irrelevant cortical commands during the neural coding of motor sequences.

The precise molecular abnormalities disrupting corticostriatal plasticity in dyskinesia are not yet understood, but substantial information is already available regarding the effects of L-DOPA treatment on the expression, phosphorylation state, intracellular trafficking, and protein associations of NMDA-receptor subunits in striatal neurons (Chase and Oh 2000; Dunah et al. 2000; Calon et al. 2003; Hallett et al. 2005; Hurley et al. 2005; Nash et al. 2005; Fiorentini et al. 2006; Gardoni et al. 2006). Two recent studies have linked L-DOPA-induced dyskinesia to an altered trafficking of the NR2B receptor subunit, whose abundance is relatively reduced in a striatal post-synaptic density-fraction, but not in total striatal homogenates from L-DOPA-treated dyskinetic rats (Fiorentini et al. 2006; Gardoni et al. 2006). Intrastriatal delivery of a cell-permeable peptide, which disrupted the interaction between NR2B and its anchoring proteins, conferred susceptibility to L-DOPA-induced AIMs to rats previously classified as non-dyskinetic (Gardoni et al. 2006). These results suggest that a relative redistribution of the NR2B subunit from synaptic to extrasynaptic membranes favours the appearance of dyskinesia, although the mechanisms through which 
this occurs remain unknown. In addition to reduced levels of NR2B, Fiorentini et al, (2006) found a relative depletion of the NMDA subunit, NR1, and of D1 receptors in a striatal postsynaptic density fraction from dyskinetic rats. Levels of the same receptor proteins were not reduced in total membrane fractions, again pointing to a perturbation of receptor trafficking (as opposed to overall receptor expression) as the core alteration in dyskinetic rats. Further work is needed to clarify the functional significance of an altered subcellular trafficking of D1 and NMDA-receptors in L-DOPA-induced dyskinesia. A relative redistribution of receptor proteins between different membrane compartments is bound to affect, on one hand, the sensitivity of the receptors for their endogenous ligands and, on the other hand, the downstream signalling events. For example, Gardoni et al, (2006) have suggested that an increased extrasynaptic expression of NR2B may cause a reduced capacity for (glutamatedependent) CREB activation in striatal neurons (but see Oh et al. 2003). In future studies, it will also be important to examine the impact of DA denervation and L-DOPA treatment on the distribution and phosphorylation of AMPA receptors, which play an essential role in synaptic plasticity (Hayashi et al. 2000; Thomas et al. 2001; Moult et al. 2006) and provide a possible target for antidyskinetic treatments (Konitsiotis et al. 2000). Whereas synaptic and molecular rearrangements associated with dyskinesia have been relatively well studied in the striatum, plastic adaptations occurring in other parts of the cortico-basal ganglionic circuitry have been poorly explored, but are likely to play an important role (Soghomonian 2006) and deserve thorough investigation. Finally, the generality of findings from 6-OHDA lesioned rats should be verified in nonhuman primate models of L-DOPA-induced dyskinesia.

\section{L-DOPA-induced presynaptic plasticity?}

Although large attention has been devoted to striatal synapses and genes, recent studies indicate that L-DOPA-induced plasticity may also affect mechanisms of L-DOPA or DA uptake, conversion, and metabolism in the brain (summarized in Fig. 2). Using the 6-OHDA lesion model of PD, Meissner et al. (Meissner et al. 2006) found that the surge in striatal extracellular DA levels elicited by a peripheral dose of L-DOPA is heavily conditioned by a prior course of L-DOPA treatment. After an i.p. injection of L-DOPA, striatal DA levels were increased in both L-DOPA-primed and non-primed animals, but to a much larger level in the former compared to the latter groups. Moreover, the larger increase in extracellular DA levels in dyskinetic rats was not matched by a proportional increase in the production of the DA metabolites, DOPAC and HVA. Thus, after a challenge injection of L-DOPA, an index of DA turnover (i.e. the ratio, DA metabolites/DA) was significantly elevated in drug-naive 
animals but not in previously L-DOPA-treated, dyskinetic rats. Taken together, these data strongly indicate that treatment with L-DOPA alters the regulation of DA release (or uptake) and DA metabolism in the striatum. In agreement with Meissner and colleagues, Ahn et al. (Ahn et al. 2004) found that an i.p. injection of L-DOPA produced a much larger increase in striatal DA levels in 6-OHDA-lesioned rats rendered dyskinetic by a prior course of L-DOPA treatment compared to non-dyskinetic animals. Interestingly, Ahn et al. (Ahn et al. 2004) could identify one key mechanism for the large DA surge occurring in dyskinetic rats, namely, a reversal of DAT function. Indeed, the L-DOPA-induced increase in extracellular DA was blocked by intrastriatal infusion of a DAT inhibitor (Ahn et al. 2004). In addition to DAT dysfunction, larger increases in extracellular DA post-drug injection may also reflect higher striatal levels of L-DOPA. In our laboratory, we have found that the concentrations of L-DOPA in the brain extracellular fluid are higher in dyskinetic rats compared to nondyskinetic cases after a peripheral drug dose, although plasma L-DOPA levels do not differ between these two conditions (Carta et al. 2006). In our study, the temporal rise and decline of striatal L-DOPA levels in dyskinetic rats matched closely the time course of the L-DOPAinduced AIMs (Carta et al. 2006). Moreover, when L-DOPA was directly infused in the striatum, even non-dyskinetic rats exhibited AIMs in a concentration-dependent fashion. These data indicate that the amount of L-DOPA present in the striatal extracellular fluid determines the acute expression of dyskinesia and its severity, at least in this rat model. Further studies will be required to assess the generality of these findings, and to determine whether a higher central bioavailability of L-DOPA in dyskinetic animals reflects treatmentrelated adaptations versus individual features that are pre-existent to treatment (the latter question will have to be addressed with techniques that allow for a longitudinal monitoring of the same animal during chronic L-DOPA treatment). Nevertheless, the above studies collectively provide evidence of presynaptic plasticity in L-DOPA-induced dyskinesia. Intriguingly, these studies also raise the possibility that individual differences in the susceptibility to dyskinesia may reflect a variation in the magnitude and kinetics of central changes in L-DOPA and DA levels following peripheral drug administration. Such a hypothesis is quite compatible with recent PET studies in PD patients, which indicate that rapid fluctuations in central DA levels are at the heart of both motor fluctuations and dyskinesia (de la Fuente-Fernandez et al. 2004a; de la Fuente-Fernandez et al. 2004b). These studies are discussed in detail below.

Presynaptic alterations in dyskinetic patients and their therapeutic implications 
The dynamics of striatal DA release following peripheral L-DOPA administration has been examined in PD patients by PET using the reversible D2 receptor ligand, $\left[{ }^{11} \mathrm{C}\right]$ raclopride (RAC). RAC PET takes advantage of a competition between endogenous DA and RAC for binding at D2 receptors. Increased levels of DA release and/or production in the striatum are thus seen as a reduction in RAC binding potential compared to baseline values. De la Fuente Fernandez and colleagues have examined changes in RAC binding potential in the striatum at 1 and 4 hours after oral administration of a standard-release preparation of L-

DOPA/carbidopa (250/25 mg). In one study, patients in the early stages of PD were followed prospectively for three years of L-DOPA treatment. Patients who developed fluctuations had a different pattern of L-DOPA-induced changes in RAC binding compared to stable responders. Thus, 1 hour post L-DOPA, the estimated increase in synaptic DA levels was 3 times larger in fluctuators compared to stable responders. The increase was also more transient, since RAC binding potential had returned to baseline by 4 hours post L-DOPA in fluctuators while central DA levels were still significantly enhanced in the stable reponders (de la Fuente-Fernandez et al. 2001). In another study, the same technique was used to examine the dynamics of striatal DA release in patients with peak-dose dyskinesia compared to non-dyskinetic PD cases. Also in this study, the patients experiencing motor complications (dyskinesia) exhibited greater changes in central DA levels at 1 hour after L-DOPA administration compared to stable L-DOPA responders (de la Fuente-Fernandez et al. 2004b). The pathophysiological importance of central pharmacokinetic mechanisms is further supported by the observation that the incidence of dyskinesia is lower in patients on treatment with direct DA agonists instead of L-DOPA (Rinne et al. 1998; Rascol et al. 2000). Differently from L-DOPA, the DA agonists have a long half-life, which prevents the occurrence of rapid and transient fluctuations in central levels of DA receptor occupancy. Unfortunately, these drugs do not provide an alternative to L-DOPA in the more advanced stages of PD, as they are less effective than the DA precursor in ameliorating PD motor symptoms. New treatment strategies are thus being devised to optimize methods of L-DOPA delivery (for review see Nyholm and Aquilonius 2004) or to reduce the need for L-DOPA using surgical approaches (Kuan and Barker 2005; Metman and O'Leary 2005). At the basic experimental level, very promising results have been recently obtained in the field of gene therapy. In rats with 6-OHDA lesions, dyskinesia and motor fluctuations can be prevented or reversed by viral vector-mediated delivery of genes achieving either a continuous L-DOPA production (Carlsson et al. 2005) or a restoration of DA storage capacity (Lee et al. 2006) in the striatum. 


\section{Presynaptic plasticity in L-DOPA-induced dyskinesia: directions for future studies}

As reviewed above, both clinical and experimental studies have now established that the concentrations and temporal changes of L-DOPA/DA in the brain extracellular fluid are critical to the occurrence of dyskinesia, and that these parameters may show variation. Interindividual variation is seen also in animal models where the extent of DA denervation is strictly controlled, similar among subjects, and stable during the course of L-DOPA treatment. Further studies are now needed to identify factors other than the extent of DA denervation, which may influence the kinetics of L-DOPA uptake, DA release and metabolism. L-DOPA enters the brain via endothelial carrier proteins (Pardridge and Oldendorf 1975; Wade and Katzman 1975), and its uptake by neurons and other cells is also dependent on carrier-mediated transport at the plasma membrane. The transport and uptake of L-DOPA may thus be affected by genetic variation in the activity of these specific carrier systems, a variation that would be pre-existent to L-DOPA treatment and even to PD itself. However, variation may also occur within the same individual over the time because of treatment-related plasticity. Potentially, each of the routes for L-DOPA uptake and conversion, and/or DA re-uptake and metabolism, which are itemized in Fig. 2, can undergo changes that affect their efficiency. Plasticity at sites post-synaptic to the nigrostriatal DA neuron may in fact modify crucial presynaptic processes that affect the handling of exogenous L-DOPA and DA in the brain. Many possibilities are at hand. For example, postsynaptic changes that cause increased glutamate transmission (Picconi et al. 2003; Robelet et al. 2004) and altered ion homeostasis in the striatum (Konradi et al. 2004) are likely to have a profound impact on the function of the DAT (Lonart and Zigmond 1991; Ahn et al. 2004). Moreover, structural and functional changes may affect tissue compartments that are involved in the transport, uptake and/or conversion of exogenous L-DOPA. For example, novel evidence indicates that L-DOPA-induced dyskinesia is associated with endothelial proliferation, angiogenesis and increased blood-brain barrier permeability in the basal ganglia nuclei (Westin et al. 2006b) and future studies will have to determine whether this phenomenon modifies the kinetics of L-DOPA entry from blood to brain. Further studies are also required to clarify the role of serotonergic fiber systems as a source of L-DOPA uptake and conversion that is likely relevant to dyskinesia. In fact, pharmacological agents that target 5-HT1A serotonin autoreceptors blunt the peak-concentration and prolong the half-life of striatal DA (Nomikos et al. 1996; Kannari et al. 2001), and exert antidyskinetic effects in PD patients (Olanow et al. 2004a; Bara-Jimenez et al. 2005). Interestingly, serotonin axons show 
a remarkable capacity for compensatory sprouting after lesions of both homotypic and heterotypic projections (Liu et al. 2003; Maeda et al. 2005), and exhibit sprouting also in response to activity-dependent production of trophic factors (Liu et al. 2004). Preliminary evidence suggests that the ascending serotonin pathways may undergo plastic changes in dyskinetic animals, at least in brain cortical regions (Carta et al. 2006).

Notwithstanding the importance of striatal synapses and genes, our comprehension of the neurochemical derangements at the basis of L-DOPA-induced dyskinesia needs to be advanced on several significant fronts. On one hand, fine abnormalities in DA release versus clearance need to be dissected using in vivo techniques that offer high temporal and spatial resolution (Gerhardt and Burmeister 2000). On the other hand, it will be important to address the impact of DA dysregulation on the release of fast neurotransmitters within the basal ganglia (i.e. GABA and glutamate). Eventually, all these studies may allow for defining the neurochemical triggers of altered firing patterns and oscillatory activities in the motor loops of the basal ganglia, which have recently emerged as a neural hallmark of dyskinesia in both rodent models (Meissner et al. 2006) and PD patients (Alonso et al. 2006).

\section{Concluding remarks}

Over the past 20 years, theories about the mechanisms of L-DOPA-induced dyskinesia appear to have swong from pre- to postsynaptic sites within the nigrostriatal DA system, but an integrated understanding of this phenomenon has remained elusive. The "presynaptic storage hypothesis" provided a first-level explanation as to why the motor response to LDOPA changed during the progression of PD. However, this theory did not account for, e.g., parallel alterations in the pharmacodynamic profile of DA agonists. In the past decade, the triad of corticostriatal terminals, dopamine receptors and medium-sized spiny neurons was recognized as being pivotal to behavioural and synaptic plasticity in the basal ganglia (for review see Hyman and Malenka 2001; Gerdeman et al. 2003b). Accordingly, a large body of experimental studies in animal models of PD focused on striatal genes and synapses as the primary locus of aberrant plasticity in L-DOPA-induced dyskinesia. Some recent studies, both clinical and experimental, have brought presynaptic factors back into the limelight, suggesting that L-DOPA-induced plasticity may also involve mechanisms of L-DOPA transport, uptake and conversion in the brain. These unexpected findings highlight the need to explore novel paths of investigation, in quest of a comprehensive pathophysiological explanation for the adverse effects of L-DOPA pharmacotherapy in PD. 


\section{Acknowledgements}

The authors' own work in this area was supported by grants from the M. J. Fox Foundation for Parkinson's Research, the Swedish National Research Council, the Swedish Parkinson Foundation, The King Gustaf V and Queen Victoria Foundation, the Elsa and Thorsten Segerfalks Foundation, the Craaford Foundation, and Hjärnfonden. 


\section{References}

Abercrombie E. D., Bonatz A. E. and Zigmond M. J. (1990) Effects of L-dopa on extracellular dopamine in striatum of normal and 6-hydroxydopamine-treated rats. Brain Res $525,36-44$.

Ahlskog J. E. and Muenter M. D. (2001) Frequency of levodopa-related dyskinesias and motor fluctuations as estimated from the cumulative literature. Mov Disord 16, 448-458.

Ahn S., Cheng C., Phillips A. G. and Lee C. S. (2004) Reversal of the dopamine transporter in the severely 6-OHDA lesioned striatum with chronic L-DOPA treatment: a Reverse Dialysis study with GBR 12909, in Abstract Viewer/Itinerary Planner, Vol. Online, p Program No. 562.563. Society for Neuroscience, Washington, DC.

Alonso F., Zamarbide I., Alegre M., Rodriguez-Oroz M. C., Guridi J., Manrique M., Valencia M., Artieda J. and Obeso J. A. (2006) Slow oscillatory activity in the subthalamic nucleus and levodopa-induced dyskinesias in Parkinson's Disease. Brain in press.

Andersson M., Hilbertson A. and Cenci M. A. (1999) Striatal fosB expression is causally linked with 1-DOPA-induced abnormal involuntary movements and the associated upregulation of striatal prodynorphin mRNA in a rat model of Parkinson's disease. Neurobiol Dis 6, 461-474.

Andersson M., Konradi C. and Cenci M. A. (2001) cAMP response element-binding protein is required for dopamine-dependent gene expression in the intact but not the dopaminedenervated striatum. J Neurosci 21, 9930-9943.

Andersson M., Westin J. E. and Cenci M. A. (2003) Time course of striatal DeltaFosB-like immunoreactivity and prodynorphin mRNA levels after discontinuation of chronic dopaminomimetic treatment. Eur J Neurosci 17, 661-666.

Arai R., Karasawa N., Geffard M. and Nagatsu I. (1995) L-DOPA is converted to dopamine in serotonergic fibers of the striatum of the rat: a double-labeling immunofluorescence study. Neurosci Lett 195, 195-198. 
Aubert I., Guigoni C., Hakansson K., Li Q., Dovero S., Barthe N., Bioulac B. H., Gross C. E., Fisone G., Bloch B. and Bezard E. (2005) Increased D1 dopamine receptor signaling in levodopa-induced dyskinesia. Ann Neurol 57, 17-26.

Bara-Jimenez W., Bibbiani F., Morris M. J., Dimitrova T., Sherzai A., Mouradian M. M. and Chase T. N. (2005) Effects of serotonin 5-HT1A agonist in advanced Parkinson's disease. Mov Disord 20, 932-936.

Betarbet R., Turner R., Chockkan V., DeLong M. R., Allers K. A., Walters J., Levey A. I. and Greenamyre J. T. (1997) Dopaminergic neurons intrinsic to the primate striatum. $J$ Neurosci 17, 6761-6768.

Bezard E., Ferry S., Mach U., Stark H., Leriche L., Boraud T., Gross C. and Sokoloff P. (2003) Attenuation of levodopa-induced dyskinesia by normalizing dopamine D3 receptor function. Nat Med 9, 762-767.

Blanchet P. J., Allard P., Gregoire L., Tardif F. and Bedard P. J. (1996) Risk factors for peak dose dyskinesia in 100 levodopa-treated parkinsonian patients. Can J Neurol Sci 23, 189-193. Braak H., Ghebremedhin E., Rub U., Bratzke H. and Del Tredici K. (2004) Stages in the development of Parkinson's disease-related pathology. Cell Tissue Res 318, 121-134.

Bravi D., Mouradian M. M., Roberts J. W., Davis T. L., Sohn Y. H. and Chase T. N. (1994) Wearing-off fluctuations in Parkinson's disease: contribution of postsynaptic mechanisms. Ann Neurol 36, 27-31.

Brotchie J. M. (2005) Nondopaminergic mechanisms in levodopa-induced dyskinesia. Mov Disord 20, 919-931.

Brown W. D., Taylor M. D., Roberts A. D., Oakes T. R., Schueller M. J., Holden J. E., Malischke L. M., DeJesus O. T. and Nickles R. J. (1999) FluoroDOPA PET shows the nondopaminergic as well as dopaminergic destinations of levodopa. Neurology 53, 1212 1218. 
Calabresi P., Pisani A., Mercuri N. B. and Bernardi G. (1996) The corticostriatal projection: from synaptic plasticity to dysfunctions of the basal ganglia. Trends Neurosci. 19, 19-24.

Calabresi P., Saiardi A., Pisani A., Baik J. H., Centonze D., Mercuri N. B., Bernardi G. and Borrelli E. (1997) Abnormal synaptic plasticity in the striatum of mice lacking dopamine D2 receptors. J Neurosci. 17, 4536-4544.

Calon F., Rajput A. H., Hornykiewicz O., Bedard P. J. and Di Paolo T. (2003) Levodopainduced motor complications are associated with alterations of glutamate receptors in Parkinson's disease. Neurobiol Dis 14, 404-416.

Carlsson T., Winkler C., Burger C., Muzyczka N., Mandel R. J., Cenci A., Bjorklund A. and Kirik D. (2005) Reversal of dyskinesias in an animal model of Parkinson's disease by continuous L-DOPA delivery using rAAV vectors. Brain 128, 559-569.

Carta M., Lindgren H., Lundblad M., Stancampiano R., Fadda F. and Cenci M. A. (2006) Role of striatal L-DOPA in the production of dyskinesia in 6-hydroxydopamine lesioned rats. J Neurochem 96, 1718-1727.

Cenci M. A. (2002) Transcription factors involved in the pathogenesis of L-DOPA-induced dyskinesia in a rat model of Parkinson's disease. Amino Acids 23, 105-109.

Cenci M. A., Lee C. S. and Bjorklund A. (1998) L-DOPA-induced dyskinesia in the rat is associated with striatal overexpression of prodynorphin- and glutamic acid decarboxylase mRNA. Eur J Neurosci 10, 2694-2706.

Centonze D., Gubellini P., Picconi B., Calabresi P., Giacomini P. and Bernardi G. (1999) Unilateral dopamine denervation blocks corticostriatal LTP. J Neurophysiol. 82, 3575-3579.

Cepeda C., Colwell C. S., Itri J. N., Chandler S. H. and Levine M. S. (1998) Dopaminergic modulation of NMDA-induced whole cell currents in neostriatal neurons in slices: contribution of calcium conductances. J Neurophysiol 79, 82-94. 
Chase T. N. (1998) Levodopa therapy: consequences of the nonphysiologic replacement of dopamine. Neurology 50, S17-25.

Chase T. N. and Oh J. D. (2000) Striatal dopamine- and glutamate-mediated dysregulation in experimental parkinsonism. Trends Neurosci 23, S86-91.

Crocker S. J., Morelli M., Wigle N., Nakabeppu Y. and Robertson G. S. (1998) D1-Receptorrelated priming is attenuated by antisense-meditated 'knockdown' of fosB expression. Brain Res Mol Brain Res 53, 69-77.

de la Fuente-Fernandez R., Schulzer M., Mak E., Calne D. B. and Stoessl A. J. (2004a) Presynaptic mechanisms of motor fluctuations in Parkinson's disease: a probabilistic model. Brain 127, 888-899.

de la Fuente-Fernandez R., Sossi V., Huang Z., Furtado S., Lu J. Q., Calne D. B., Ruth T. J. and Stoessl A. J. (2004b) Levodopa-induced changes in synaptic dopamine levels increase with progression of Parkinson's disease: implications for dyskinesias. Brain 127, 2747-2754.

de la Fuente-Fernandez R., Lu J. Q., Sossi V., Jivan S., Schulzer M., Holden J. E., Lee C. S., Ruth T. J., Calne D. B. and Stoessl A. J. (2001) Biochemical variations in the synaptic level of dopamine precede motor fluctuations in Parkinson's disease: PET evidence of increased dopamine turnover. Ann Neurol 49, 298-303.

Di Monte D. A., McCormack A., Petzinger G., Janson A. M., Quik M. and Langston W. J. (2000) Relationship among nigrostriatal denervation, parkinsonism, and dyskinesias in the MPTP primate model. Mov Disord 15, 459-466.

Dunah A. W., Wang Y., Yasuda R. P., Kameyama K., Huganir R. L., Wolfe B. B. and Standaert D. G. (2000) Alterations in subunit expression, composition, and phosphorylation of striatal N-methyl-D-aspartate glutamate receptors in a rat 6-hydroxydopamine model of Parkinson's disease. Mol Pharmacol 57, 342-352.

Erickson J. D., Schafer M. K., Bonner T. I., Eiden L. E. and Weihe E. (1996) Distinct pharmacological properties and distribution in neurons and endocrine cells of two isoforms of the human vesicular monoamine transporter. Proc Natl Acad Sci U S A 93, 5166-5171. 
Fahn S. (2000) The spectrum of levodopa-induced dyskinesias. Ann Neurol 47, S2-9; discussion S9-11.

Fahn S. (2003) Description of Parkinson's disease as a clinical syndrome. Ann N Y Acad Sci 991, $1-14$

Fearnley J. M. and Lees A. J. (1991) Ageing and Parkinson's disease: substantia nigra regional selectivity. Brain 114, 2283-2301.

Finkelstein D. I., Stanic D., Parish C. L., Tomas D., Dickson K. and Horne M. K. (2000) Axonal sprouting following lesions of the rat substantia nigra. Neuroscience 97, 99-112.

Fiorentini C., Gardoni F., Spano P., Di Luca M. and Missale C. (2003) Regulation of dopamine D1 receptor trafficking and desensitization by oligomerization with glutamate $\mathrm{N}$ methyl-D-aspartate receptors. J Biol Chem 278, 20196-20202.

Fiorentini C., Rizzetti M. C., Busi C., Bontempi S., Collo G., Spano P. and Missale C. (2006) Loss of synaptic D1 dopamine/N-methyl-D-aspartate glutamate receptor complexes in LDOPA-induced dyskinesia in the rat. Mol Pharmacol 69, 805-812.

Gardoni F., Picconi B., Ghiglieri V., Polli F., Bagetta V., Bernardi G., Cattabeni F., Di Luca M. and Calabresi P. (2006) A critical interaction between NR2B and MAGUK in L-DOPA induced dyskinesia. J Neurosci 26, 2914-2922.

Gasser T. (2005) Genetics of Parkinson's disease. Curr Opin Neurol 18, 363-369.

Gerfen C. R., Miyachi S., Paletzki R. and Brown P. (2002) D1 dopamine receptor supersensitivity in the dopamine-depleted striatum results from a switch in the regulation of ERK1/2/MAP kinase. J Neurosci 22, 5042-5054.

Gerdeman G. L., Partridge J. G., Lupica C. R. and Lovinger D. M. (2003a) It could be habit forming: drugs of abuse and striatal synaptic plasticity. Trends Neurosci 26, 184-192. 
Gerhardt G. A. and Burmeister J. J. (2000) Voltammetry in vivo for chemical analysis of the nervous system, in Encyclopedia of Analytical Chemistry (Meyers R. A., ed.), pp 710-773. John Wiley and Sons Ltd., Chichester.

Grandas F., Galiano M. L. and Tabernero C. (1999) Risk factors for levodopa-induced dyskinesias in Parkinson's disease. J Neurol 246, 1127-1133.

Graybiel A. M. (1995) Building action repertoires: memory and learning functions of the basal ganglia. Curr Opin Neurobiol 5, 733-741.

Greengard P., Nairn A. C., Girault J. A., Ouimet C. C., Snyder G. L., Fisone G., Allen P. B., Fienberg A. and Nishi A. (1998) The DARPP-32/protein phosphatase-1 cascade: a model for signal integration. Brain Res Rev, 274-284.

Guerra M. J., Liste I. and Labandeira-Garcia J. L. (1997) Effects of lesions of the nigrostriatal pathway and of nigral grafts on striatal serotonergic innervation in adult rats. Neuroreport $\mathbf{8}$, $3485-3488$.

Hallett P. J., Spoelgen R., Hyman B. T., Standaert D. G. and Dunah A. W. (2006) Dopamine D1 activation potentiates striatal NMDA receptors by tyrosine phosphorylation-dependent subunit trafficking. J Neurosci. 26, 4690-4700.

Hallett P. J., Dunah A. W., Ravenscroft P., Zhou S., Bezard E., Crossman A. R., Brotchie J. M. and Standaert D. G. (2005) Alterations of striatal NMDA receptor subunits associated with the development of dyskinesia in the MPTP-lesioned primate model of Parkinson's disease. Neuropharmacology 48, 503-516.

Hayashi Y., Shi S. H., Esteban J. A., Piccini A., Poncer J. C. and Malinow R. (2000) Driving AMPA receptors into synapses by LTP and CaMKII: requirement for GluR1 and PDZ domain interaction. Science 287, 2262-2267.

Hurley M. J., Jackson M. J., Smith L. A., Rose S. and Jenner P. (2005)

Immunoautoradiographic analysis of NMDA receptor subunits and associated postsynaptic 
density proteins in the brain of dyskinetic MPTP-treated common marmosets. Eur J Neurosci 21, 3240-3250.

Hyman S. E. and Malenka R. C. (2001) Addiction and the brain: the neurobiology of compulsion and its persistence. Nat Rev Neurosci 2, 695-703.

Jenner P. (2000) Factors influencing the onset and persistence of dyskinesia in MPTP-treated primates. Ann Neurol 47, S90-99; discussion S99-104.

Kannari K., Yamato H., Shen H., Tomiyama M., Suda T. and Matsunaga M. (2001) Activation of 5-HT(1A) but not 5-HT(1B) receptors attenuates an increase in extracellular dopamine derived from exogenously administered L-DOPA in the striatum with nigrostriatal denervation. J Neurochem 76, 1346-1353.

Kerr J. N. and Wickens J. R. (2001) Dopamine D-1/D-5 receptor activation is required for long-term potentiation in the rat neostriatum in vitro. $J$ Neurophysiol. 85, 117-124.

Konitsiotis S., Blanchet P. J., Verhagen Metman L., Lamers E. and Chase T. N. (2000) AMPA receptor blockade improves levodopa-induced dyskinesia in MPTP monkeys. Neurology 54, 1589-1595.

Konradi C., Westin J. E., Carta M., Eaton M. E., Kuter K., Dekundy A., Lundblad M. and Cenci M. A. (2004) Transcriptome analysis in a rat model of L-DOPA-induced dyskinesia. Neurobiol Dis 17, 219-236.

Kuan W. L. and Barker R. A. (2005) New therapeutic approaches to Parkinson's disease including neural transplants. Neurorehabil Neural Repair 19, 155-181.

Lee C. S., Cenci M. A., Schulzer M. and Bjorklund A. (2000) Embryonic ventral mesencephalic grafts improve levodopa-induced dyskinesia in a rat model of Parkinson's disease. Brain 123 ( Pt 7), 1365-1379. 
Lee F. J. S. X., S.; Pei, L.; Vukusic, B.; Chery, N.; Wang, Y.; Wang, Y.T.; Niznik, H.B.; Yu, X.-m.; Liu, F. (2002) Dual Regulation of NMDA Receptor Functions by Direct ProteinProtein Interactions with the Dopamine D1 Receptor. Cell 111, 219-230.

Lee W. Y., Lee E. A., Jeon M. Y., Kang H. Y. and Park Y. G. (2006) Vesicular monoamine transporter-2 and aromatic 1-amino acid decarboxylase gene therapy prevents development of motor complications in parkinsonian rats after chronic intermittent 1-3,4dihydroxyphenylalanine administration. Exp Neurol 197, 215-224

Leenders K. L., Palmer A. J., Quinn N., Clark J. C., Firnau G., Garnett E. S., Nahmias C., Jones T. and Marsden C. D. (1986) Brain dopamine metabolism in patients with Parkinson's disease measured with positron emission tomography. J Neurol Neurosurg Psychiatry 49, 853-860.

Leveque J. C., Macias W., Rajadhyaksha A., Carlson R. R., Barczak A., Kang S., Li X. M., Coyle J. T., Huganir R. L., Heckers S. and Konradi C. (2000) Intracellular modulation of NMDA receptor function by antipsychotic drugs. J Neurosci 20, 4011-4020.

Liu Y., Ishida Y., Shinoda K. and Nakamura S. (2003) Interaction between serotonergic and noradrenergic axons during axonal regeneration. Exp Neurol 184, 169-178.

Liu Y., Ishida Y., Shinoda K., Furukawa S. and Nakamura S. (2004) Opposite morphological responses of partially denervated cortical serotonergic and noradrenergic axons to repeated stress in adult rats. Brain Res Bull 64, 67-74.

Lonart G. and Zigmond M. J. (1991) High glutamate concentrations evoke $\mathrm{Ca}(++)$ independent dopamine release from striatal slices: a possible role of reverse dopamine transport. J Pharmacol Exp Ther 256, 1132-1138.

Lopez-Real A., Rodriguez-Pallares J., Guerra M. J. and Labandeira-Garcia J. L. (2003) Localization and functional significance of striatal neurons immunoreactive to aromatic Lamino acid decarboxylase or tyrosine hydroxylase or tyrosine hydroxylase in rat Parkinsonian models. Brain Res 969, 135-146. 
Lundblad M., Picconi B., Lindgren H. and Cenci M. A. (2004) A model of L-DOPA-induced dyskinesia in 6-hydroxydopamine lesioned mice: relation to motor and cellular parameters of nigrostriatal function. Neurobiol Dis 16, 110-123.

Lundblad M., Andersson M., Winkler C., Kirik D., Wierup N. and Cenci M. A. (2002) Pharmacological validation of behavioural measures of akinesia and dyskinesia in a rat model of Parkinson's disease. Eur J Neurosci 15, 120-132.

Maeda T., Nagata K., Yoshida Y. and Kannari K. (2005) Serotonergic hyperinnervation into the dopaminergic denervated striatum compensates for dopamine conversion from exogenously administered 1-DOPA. Brain Res 1046, 230-233.

Marsden C. D. (1990) Parkinson's disease. Lancet 335, 948-952.

Mayeux R. (2003) Epidemiology of neurodegeneration. Annu Rev Neurosci 26, 81-104.

Mazzella L., Yahr M. D., Marinelli L., Huang N., Moshier E. and Di Rocco A. (2005) Dyskinesias predict the onset of motor response fluctuations in patients with Parkinson's disease on L-dopa monotherapy. Parkinsonism Relat Disord 11, 151-155.

Meissner W., Ravenscroft P., Reese R., Harnack D., Morgenstern R., Kupsch A., Klitgaard H., Bioulac B., Gross C. E., Bezard E. and Boraud T. (2006) Increased slow oscillatory activity in substantia nigra pars reticulata triggers abnormal involuntary movements in the 6OHDA-lesioned rat in the presence of excessive extracelullar striatal dopamine. Neurobiol Dis 22, 586-598.

Melamed E., Hefti F. and Wurtman R. J. (1980) Nonaminergic striatal neurons convert exogenous L-dopa to dopamine in parkinsonism. Ann Neurol. 8, 558-563.

Metman L. V. and O'Leary S. T. (2005) Role of surgery in the treatment of motor complications. Mov Disord 20 Suppl 11, S45-56. 
Metman L. V., Konitsiotis S. and Chase T. N. (2000) Pathophysiology of motor response complications in Parkinson's disease: hypotheses on the why, where, and what. Mov Disord 15, 3-8.

Miller D. W. and Abercrombie E. D. (1999) Role of high-affinity dopamine uptake and impulse activity in the appearance of extracellular dopamine in striatum after administration of exogenous L-DOPA: studies in intact and 6-hydroxydopamine-treated rats. J Neurochem 72, 1516-1522.

Morrish P. K., Sawle G. V. and Brooks D. J. (1996) An [18F]dopa-PET and clinical study of the rate of progression in Parkinson's disease. Brain 119 ( Pt 2), 585-591.

Moult P. R., Gladding C. M., Sanderson T. M., Fitzjohn S. M., Bashir Z. I., Molnar E. and Collingridge G. L. (2006) Tyrosine phosphatases regulate AMPA receptor trafficking during metabotropic glutamate receptor-mediated long-term depression. J Neurosci 26, 2544-2554.

Mouradian M. M., Juncos J. L., Fabbrini G. and Chase T. N. (1987) Motor fluctuations in Parkinson's disease: pathogenetic and therapeutic studies. Ann Neurol 22, 475-479.

Mouradian M. M., Juncos J. L., Fabbrini G., Schlegel J., Bartko J. J. and Chase T. N. (1988) Motor fluctuations in Parkinson's disease: central pathophysiological mechanisms, Part II. Ann Neurol 24, 372-378.

Mouradian M. M., Heuser I. J., Baronti F., Fabbrini G., Juncos J. L. and Chase T. N. (1989) Pathogenesis of dyskinesias in Parkinson's disease. Ann Neurol 25, 523-526.

Nash J. E., Johnston T. H., Collingridge G. L., Garner C. C. and Brotchie J. M. (2005) Subcellular redistribution of the synapse-associated proteins PSD-95 and SAP97 in animal models of Parkinson's disease and L-DOPA-induced dyskinesia. Faseb J 19, 583-585.

Nicola S. M., Surmeier J. and Malenka R. C. (2000) Dopaminergic modulation of neuronal excitability in the striatum and nucleus accumbens. Annu Rev Neurosci. 23, 185-215. 
Nirenberg M. J., Liu Y., Peter D., Edwards R. H. and Pickel V. M. (1995) The vesicular monoamine transporter 2 is present in small synaptic vesicles and preferentially localizes to large dense core vesicles in rat solitary tract nuclei. Proc Natl Acad Sci U S A 92, 8773-8777.

Nomikos G. G., Arborelius L., Hook B. B., Hacksell U. and Svensson T. H. (1996) The 5HT1A receptor antagonist (S)-UH-301 decreases dopamine release in the rat nucleus accumbens and striatum. J Neural Transm 103, 541-554.

Nutt J. G. (1992) Dyskinesia induced by levodopa and dopamine agonists in patients with Parkinson's disease, in Drug-induced movement disorders (Lang A. E. and Weiner W. J., eds), pp 281-314. Futura Publishing Co., Inc., Mount Kisko.

Nutt J. G. and Holford N. H. (1996) The response to levodopa in Parkinson's disease: imposing pharmacological law and order. Ann Neurol 39, 561-573.

Nutt J. G., Woodward W. R., Carter J. H. and Gancher S. T. (1992) Effect of long-term therapy on the pharmacodynamics of levodopa. Relation to on-off phenomenon. Arch Neurol 49, 1123-1130.

Nutt J. G., Carter J. H., Lea E. S. and Woodward W. R. (1997) Motor fluctuations during continuous levodopa infusions in patients with Parkinson's disease. Mov Disord 12, 285-292.

Nyholm D. and Aquilonius S. M. (2004) Levodopa infusion therapy in Parkinson disease: state of the art in 2004. Clin Neuropharmacol 27, 245-256.

Obeso J. A., Rodriguez-Oroz M., Marin C., Alonso F., Zamarbide I., Lanciego J. L. and Rodriguez-Diaz M. (2004) The origin of motor fluctuations in Parkinson's disease: importance of dopaminergic innervation and basal ganglia circuits. Neurology 62, S17-30.

Oh J. D., Chartisathian K., Ahmed S. M. and Chase T. N. (2003) Cyclic AMP responsive element binding protein phosphorylation and persistent expression of levodopa-induced response alterations in unilateral nigrostriatal 6-OHDA lesioned rats. J Neurosci Res. 72, 768-780. 
Olanow C. W., Damier P., Goetz C. G., Mueller T., Nutt J., Rascol O., Serbanescu A., Deckers F. and Russ H. (2004a) Multicenter, open-label, trial of sarizotan in Parkinson disease patients with levodopa-induced dyskinesias (the SPLENDID Study). Clin Neuropharmacol 27, 58-62.

Olanow C. W., Agid Y., Mizuno Y., Albanese A., Bonuccelli U., Damier P., De Yebenes J., Gershanik O., Guttman M., Grandas F., Hallett M., Hornykiewicz O., Jenner P., Katzenschlager R., Langston W. J., LeWitt P., Melamed E., Mena M. A., Michel P. P., Mytilineou C., Obeso J. A., Poewe W., Quinn N., Raisman-Vozari R., Rajput A. H., Rascol O., Sampaio C. and Stocchi F. (2004b) Levodopa in the treatment of Parkinson's disease: current controversies. Mov Disord 19, 997-1005.

Pardridge W. M. and Oldendorf W. H. (1975) Kinetic analysis of blood-brain barrier transport of amino acids. Biochim Biophys Acta 401, 128-136.

Parish C. L., Stanic D., Drago J., Borrelli E., Finkelstein D. I. and Horne M. K. (2002) Effects of long-term treatment with dopamine receptor agonists and antagonists on terminal arbor size. Eur J Neurosci 16, 787-794.

Partridge J. G., Tang K. C. and Lovinger D. M. (2000) Regional and postnatal heterogeneity of activity-dependent long-term changes in synaptic efficacy in the dorsal striatum. $J$ Neurophysiol. 84, 1422-1429.

Pavon N., Martin A. B., Mendialdua A. and Moratalla R. (2006) ERK phosphorylation and FosB expression are associated with L-DOPA-induced dyskinesia in hemiparkinsonian mice. Biol Psychiatry 59, 64-74.

Pearce R. K., Banerji T., Jenner P. and Marsden C. D. (1998) De novo administration of ropinirole and bromocriptine induces less dyskinesia than L-dopa in the MPTP-treated marmoset. Mov Disord 13, 234-241.

Peppe A., Dambrosia J. M. and Chase T. N. (1993) Risk factors for motor response complications in L-dopa-treated parkinsonian patients. Adv Neurol 60, 698-702. 
Peter D., Liu Y., Sternini C., de Giorgio R., Brecha N. and Edwards R. H. (1995) Differential expression of two vesicular monoamine transporters. J Neurosci 15, 6179-6188.

Picconi B., Centonze D., Hakansson K., Bernardi G., Greengard P., Fisone G., Cenci M. A. and Calabresi P. (2003) Loss of bidirectional striatal synaptic plasticity in L-DOPA-induced dyskinesia. Nat Neurosci 6, 501-506.

Porritt M. J., Batchelor P. E., Hughes A. J., Kalnins R., Donnan G. A. and Howells D. W. (2000) New dopaminergic neurons in Parkinson's disease striatum. Lancet 356, 44-45.

Raevskii K. S., Gainetdinov R. R., Budygin E. A., Mannisto P. and Wightman M. (2002) Dopaminergic transmission in the rat striatum in vivo in conditions of pharmacological modulation. Neurosci Behav Physiol 32, 183-188.

Rajput A. H., Fenton M. E., Birdi S., Macaulay R., George D., Rozdilsky B., Ang L. C., Senthilselvan A. and Hornykiewicz O. (2002) Clinical-pathological study of levodopa complications. Mov Disord 17, 289-296.

Rascol O., Brooks D. J., Korczyn A. D., De Deyn P. P., Clarke C. E. and Lang A. E. (2000) A five-year study of the incidence of dyskinesia in patients with early Parkinson's disease who were treated with ropinirole or levodopa. 056 Study Group. N Engl J Med 342, 14841491.

Reynolds J. N., Hyland B. I. and Wickens J. R. (2001) A cellular mechanism of rewardrelated learning. Nature 413, 67-70.

Rinne U. K., Bracco F., Chouza C., Dupont E., Gershanik O., Marti Masso J. F., Montastruc J. L. and Marsden C. D. (1998) Early treatment of Parkinson's disease with cabergoline delays the onset of motor complications. Results of a double-blind levodopa controlled trial. The PKDS009 Study Group. Drugs 55 Suppl 1, 23-30.

Robelet S., Melon C., Guillet B., Salin P. and Kerkerian-Le Goff L. (2004) Chronic L-DOPA treatment increases extracellular glutamate levels and GLT1 expression in the basal ganglia in a rat model of Parkinson's disease. Eur J Neurosci 20, 1255-1266. 
Sarre S., De Klippel N., Herregodts P., Ebinger G. and Michotte Y. (1994) Biotransformation of locally applied L-dopa in the corpus striatum of the hemi-parkinsonian rat studied with microdialysis. Naunyn Schmiedebergs Arch Pharmacol 350, 15-21.

Schrag A. and Quinn N. (2000) Dyskinesias and motor fluctuations in Parkinson's disease. A community-based study. Brain 123 ( Pt 11), 2297-2305.

Seibyl J. P., Marek K. L., Quinlan D., Sheff K., Zoghbi S., Zea-Ponce Y., Baldwin R. M., Fussell B., Smith E. O., Charney D. S. and et al. (1995) Decreased single-photon emission computed tomographic [123I]beta-CIT striatal uptake correlates with symptom severity in Parkinson's disease. Ann Neurol 38, 589-598.

Sgambato V., Pages C., Rogard M., Besson M. J. and J. C. (1998) Extracellular signalregulated kinase (ERK) controls immediate early gene induction on corticostriatal stimulation. J Neurosci. 18, 8814-8825.

Soghomonian J. J. (2006) L-DOPA-induced dyskinesia in adult rats with a unilateral 6OHDA lesion of dopamine neurons is paralleled by increased c-fos gene expression in the subthalamic nucleus. Eur J Neurosci 23, 2395-2403.

St-Hilaire M., Landry E., Levesque D. and Rouillard C. (2005) Denervation and repeated LDOPA induce complex regulatory changes in neurochemical phenotypes of striatal neurons: implication of a dopamine D1-dependent mechanism. Neurobiol Dis. 20, 450-460.

Stanic D., Finkelstein D. I., Bourke D. W., Drago J. and Horne M. K. (2003) Timecourse of striatal re-innervation following lesions of dopaminergic SNpc neurons of the rat. Eur $J$ Neurosci 18, 1175-1188.

Tanaka H., Kannari K., Maeda T., Tomiyama M., Suda T. and Matsunaga M. (1999) Role of serotonergic neurons in L-DOPA-derived extracellular dopamine in the striatum of 6-OHDAlesioned rats. Neuroreport 10, 631-634. 
Thomas M. J., Beurrier C., Bonci A. and Malenka R. C. (2001) Long-term depression in the nucleus accumbens: a neural correlate of behavioral sensitization to cocaine. Nat Neurosci 4, 1217-1223.

Verhagen Metman L., Locatelli E. R., Bravi D., Mouradian M. M. and Chase T. N. (1997) Apomorphine responses in Parkinson's disease and the pathogenesis of motor complications. Neurology 48, 369-372.

Wachtel S. R. and Abercrombie E. D. (1994) L-3,4-dihydroxyphenylalanine-induced dopamine release in the striatum of intact and 6-hydroxydopamine-treated rats: differential effects of monoamine oxidase A and B inhibitors. J Neurochem 63, 108-117.

Wade L. A. and Katzman R. (1975) Synthetic amino acids and the nature of L-DOPA transport at the blood-brain barrier. J Neurochem 25, 837-842.

Westin J. E., Vercammen L., Konradi C. and Cenci M. A. (2006a) Spatio-temporal pattern of striatal ERK1/2 phosphorylation in a rat model of L-DOPA-induced dyskinesia and the role of dopamine D1 receptors. submitted.

Westin J. E., Lindgren H. S., Gardi J., Nyengaard J. R., Brundin P., Mohapel P. and Cenci M. A. (2006b) Endothelial proliferation and increased blood-brain barrier permeability in the basal ganglia in a rat model of L-DOPA-induced dyskinesia. $J$ Neurosci, accepted.

Winkler C., Kirik D., Bjorklund A. and Cenci M. A. (2002) L-DOPA-induced dyskinesia in the intrastriatal 6-hydroxydopamine model of parkinson's disease: relation to motor and cellular parameters of nigrostriatal function. Neurobiol Dis 10, 165-186.

Zigmond M. J., Abercrombie E. D., Berger T. W., Grace A. A. and Stricker E. M. (1990) Compensations after lesions of central dopaminergic neurons: some clinical and basic implications. Trends Neurosci 13, 290-296. 


\section{Legends to Figures.}

\section{Fig 1.}

Schematic reconstruction of the changes in the dyskinesia-threshold dose of L-DOPA that follow an acute nigrostriatal lesion and chronic treatment with L-DOPA in rodents. After a severe dopaminergic lesion there is a rapid and dramatic reduction in the dose required to elicit dyskinesia with acute L-DOPA treatment (Lundblad et al. 2004). Chronic L-DOPA treatment further lowers the dyskinesia-threshold dose over time (hypothetic curve based on unpublished observations from Lundblad and Cenci).

\section{Fig. 2.}

Routes of L-DOPA uptake and conversion before (upper panel) and after (lower panel) a lesion of the nigrostriatal dopamine pathway. Severe dopamine-denervating lesions greatly increase the contribution of non-nigrostriatal routes to the handling of exogenous L-DOPA.

\section{Fig. 3.}

Schematic drawing of a medium-sized spiny neuron with an afferent corticostriatal terminal. The drawing highlights signalling components that several independent studies have implicated in the abnormal post-synaptic plasticity associated with L-DOPA-induced dyskinesia. The upper part of the drawing represents a dendritic spine with a cluster of glutamate receptors (ionotropic, NMDA and AMPA; metabotropic, mGlu), in close juxtaposition to the D1 dopamine receptor, here represented as a complex between the transmembrane receptor and its signal-transduction machinery (stimulatory G protein, Gs, and adenylate cyclase, AC). Stimulation of glutamate and D1-receptors leads to activation of calcium and cAMP-dependent second messenger pathways, which converge on extracellular signal-regulated kinases (ERK1/2). In turn, ERK1/2 can activate, either directly or indirectly, some transcription factors in the cell nucleus (lower part of the drawing), such as CREB and Elk-1 (note that the role of these two transcription factors in dyskinesia has not yet been proven). After phosphorylation of specific residues, CREB and Elk-1 can interact with enhancer elements in the promoter region of several genes (CRE, cAMP response element; and SRE, serum response element). FosB and its truncated splice variant, $\Delta \mathrm{FosB}$, are inducible transcription factors that are greatly upregulated by dyskinesiogenic L-DOPA 
treatment, and can bind to both CRE- and AP-1-like enhancers, driving the expression of lateresponse genes. PP-1, protein phosphatase 1; Ras-B-Raf-MEK, signalling components upstream of ERK1/2 in a typical calcium-dependent activation cascade. All the other abbreviations and signalling steps contained in this drawing are explained in the text. Arrows indicate either activation or potentiation.

Fig 1

\section{L-DOPA threshold dose for dyskinesia}

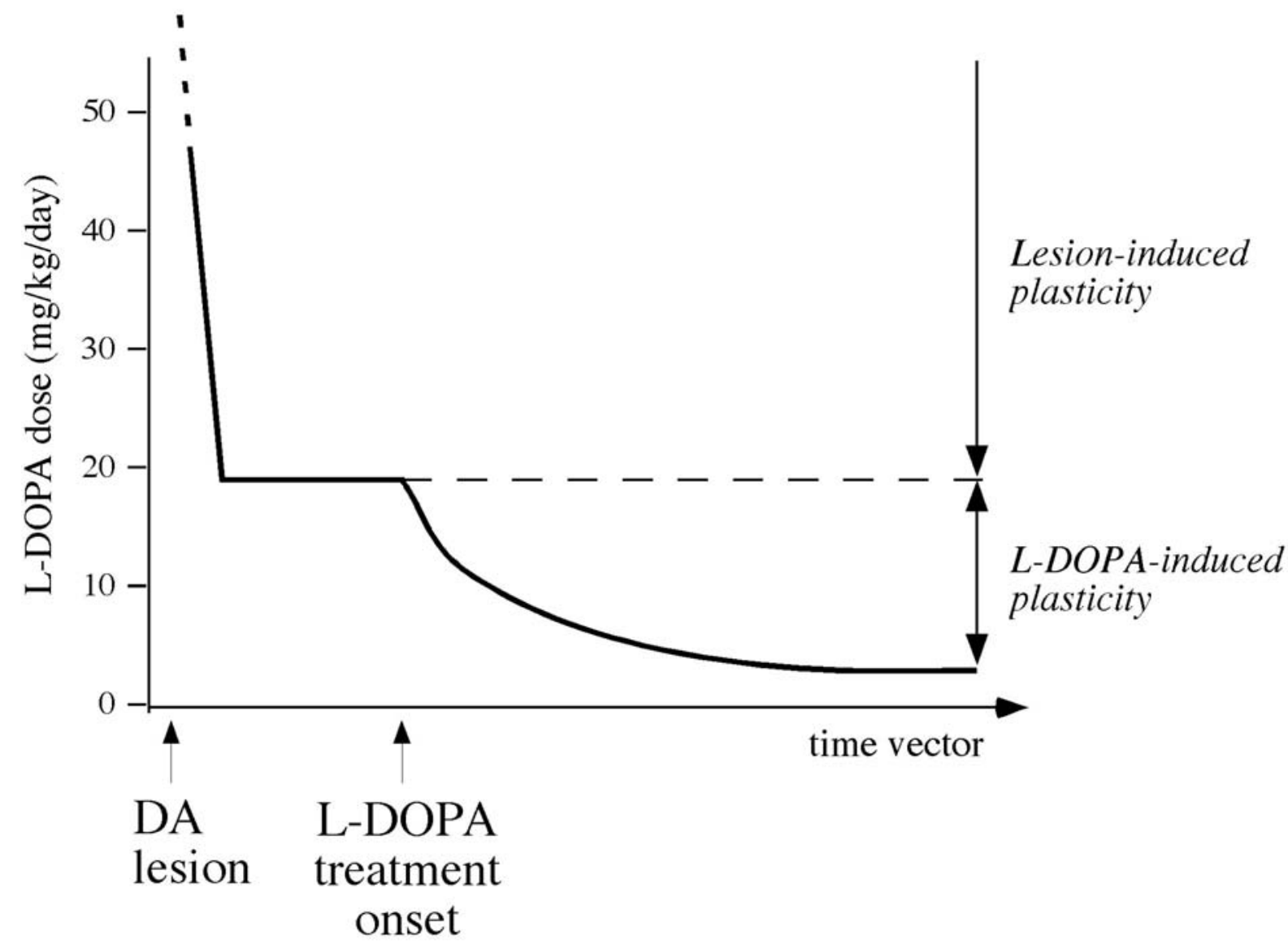


Fig 2

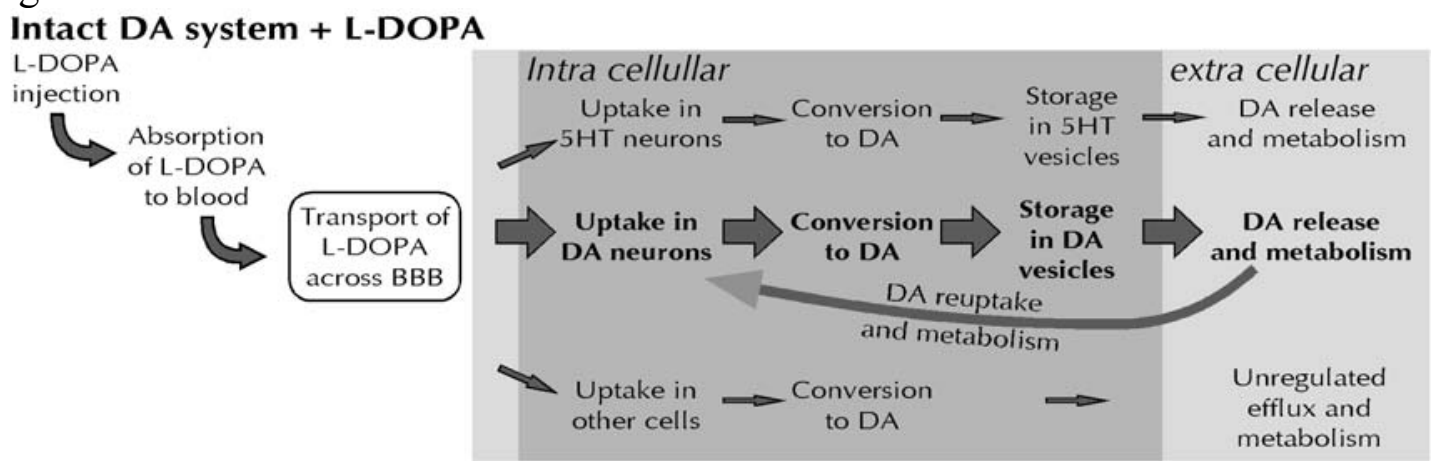

Lesioned DA system + L-DOPA

intration cellullar


Fig 3

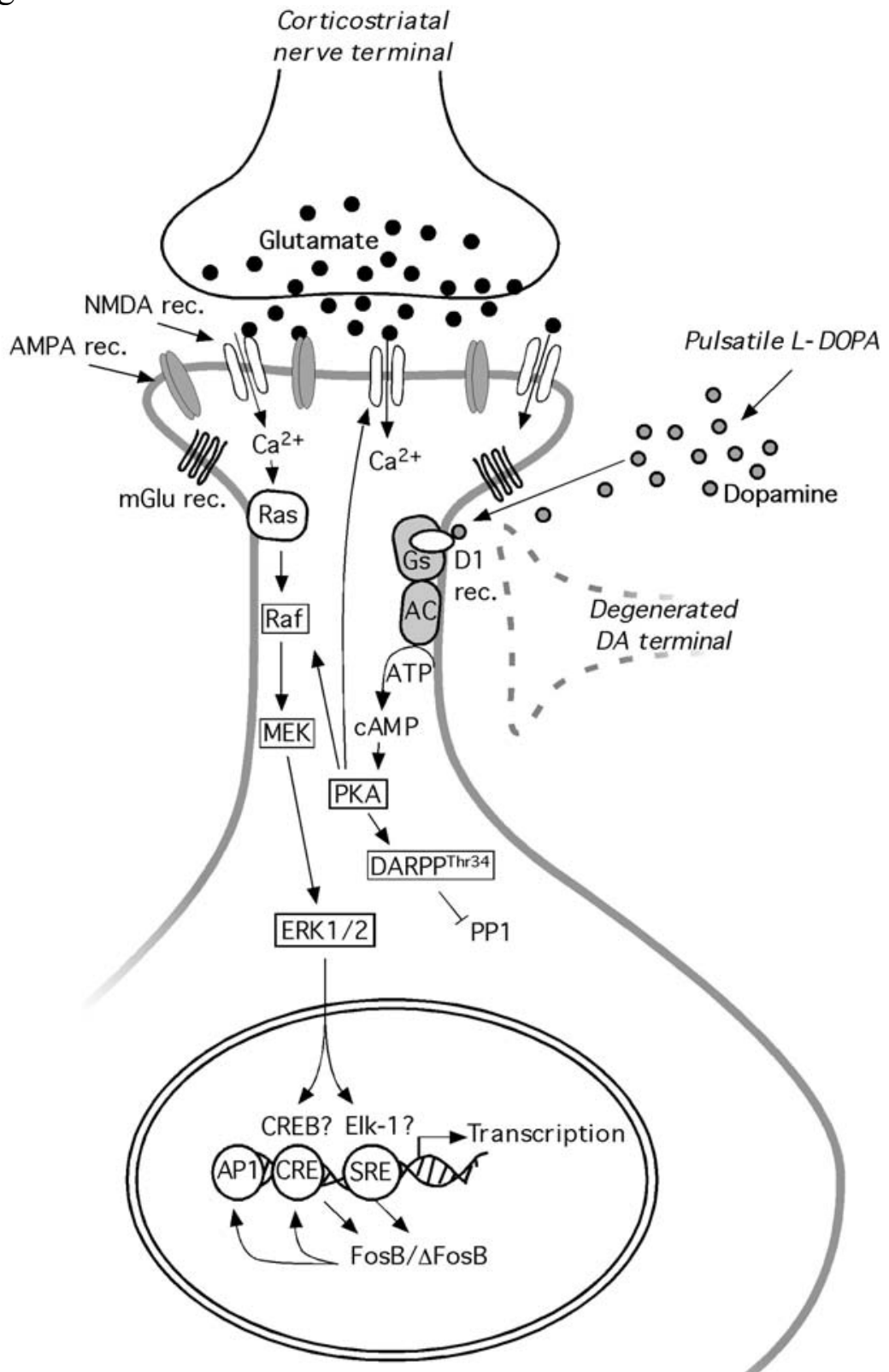

